\title{
Columns and packing methods
}

\section{J. Dingenen}

Janssen Research Foundation, Turnoutsseweg 30, B-2340 Beerse, Belgium

A lot of research has been done to develop methods which allowed to reproducibly fill analytical columns. Nowadays, it's no longer a problem to pack efficient columns with a broad variety of packing materials and particle sizes. However, from a technical point of view, it's not so easy to fill larger diameter columns using the same technology. Therefore, alternative methods had to be developed. In this contribution an overview is given of the most important technologies which are nowadays commercially available to pack preparative columns for laboratory and production scale purposes.

$\mathrm{t}$ goes without saying that the column is the most important part of a preparative chromatography system. Avoiding to take a point of view in the never ending discussion about the necessity of efficiency in preparative chromatography, it is certainly a fact that in preparative chromatography a certain number of theoretical plates are required to obtain a reasonable throughput per unit time.

For a given type of packing material the efficiency of a column is mainly determined by how the column is packed and how long the bed length is. An improvement in the methodology of column packing automatically results in reaching the required efficiency with shorter bed lengths. From an economical point of view, this reflects itself immediately in a lower cost of operation.

The quality of a certain packing technique is easy to describe by means of a few well-defined parameters:

- The efficiency expressed in terms of reduced plate height.

- The ability to reach the same reduced plate height values over a long period of time.

- The stability of the packed bed, or in other words the utmost important factor to operate a continuous process, the long-term stability of the column.

From a practical point of view, the process technical efforts necessary to be able to reproducibly fill columns of good quality are, of course, very important. Interesting are those techniques that allow successful filling of a column with a chosen stationary phase without a lot of investment in specific equipment and technical skills. Therefore, in preparative chromatography the column packing technology is as important as in analytical chromatography. A good method should allow to pack columns with a high efficiency, a good reproducibility as well as a good permeability. In this contribution only elution chromatography in axial flow will be discussed. (Excluded are radial flow and centrifugal techniques).

\section{Packing methods}

There exists two methods to fill columns:

- dry packing,

- slurry packing (filtration technique).

The dry filling method is easy to perform, but the slurry method gives, especially for smaller particles, more efficient and more reproducible columns.

\section{Dry packing method}

The simplest form of dry packing is the tap-fill method, consisting of tapping the column on a hard surface while the packing is added via a stationary funnel fitted with a distribution head (perforated plate or wire screen bottom, covering nearly the whole cross sectional area of the column). If this procedure is carried out manually, it is very difficult to obtain two columns with the same efficiency. However, with a simple mechanical filling device, it is possible to reproducibly fill columns up to a packing weight of 3 kilogram. Such a mechanical filling apparatus consists of a motor with an eccentric crank that lifts the column about 120 times per minute about 2 centimetres high and drops it afterwards on a hard surface. During this tapping action, the packing material is continuously added from a reservoir at a rate of about 3 to 4 grams per minute.

However, lipophilic chemically modified phases are, due to the build up of static charges, very difficult to dry pack. Furthermore, it is also not possible to dry pack efficient columns with packing materials having particle sizes below $20-25 \mu \mathrm{m}$. An example of a mechanical filling device is given in figure 1 .

The use of modified Büchi glass columns with an internal diameter of $70 \mathrm{~mm}$, mechanically dry packed with $25-$ $40 \mu \mathrm{m}$ packing materials has been experienced in our laboratories as a very interesting chromatographic tool, due to:

- The packing is relatively homogeneous and stable.

- For a lot of chromatographic separations, the column efficiency is sufficient to separate a certain amount of product within an acceptable time period.

- The advantages of glass: the very smooth surface, the high chemical inertness and the possibility of visual observations.

- The mechanical filling of the column can be performed without supervision.

- The investments for column hardware and filling device are relatively small. 



b.

Figure 1. Mechanical filling device for the dry packing of columns a) Schematic drawing b) Practical realisation.

The dry packing method has certainly proven its usefulness, but for pilot plant or production scale applications, the slurry packing method is much more attractive.

\section{Slurry packing method}

It is certainly not within the scope of this contribution to summarise all the different methods that have been developed in the past to fill analytical columns by means of the slurry packing technique. However, with the growing interest for combinatorial chemistry and parallel synthesis where a lot of products need to be separated or purified within a short period of time, an increased interest in small scale preparative chromatography, using both analytical and preparative columns up to one inch in diameter, can be observed.

Although, a lot of chromatography suppliers offer prepacked columns up to a diameter of $50 \mathrm{~mm}$ or more, it is probably interesting to briefly show the instrumentation and working method to fill small scale preparative columns. A schematic drawing of the equipment used in our laboratories to fill analytical and preparative (one inch) columns, is given in figure 2.

For the hardware of our one-inch columns we are standardised on material supplied by Jour Research.

The packing procedure for a 1 inch column of $25 \mathrm{~cm}$ length is described below

$66 \mathrm{~g}$ of packing material are weighed in an Erlenmeyer flask. About $180 \mathrm{~mL}$ of a suitable slurry solvent are added. The mixture is placed in an ultrasonic bath for 5 minutes. Thereafter, the homogeneous slurry is poured into the column-packing reservoir combination. The pump is connected and the packing process is started at 400 bar. After 5 seconds the packing pressure is increased to 700 bar. A total volume of $1000 \mathrm{~mL}$ of dri ver solvent is pumped through the column. After the packing process is completed, the system is kept under static pressure for about 20 minutes before the column is removed from the filling reservoir.

In principal, large diameter columns can be filled with the procedures used to fill analytical columns. However, to achieve successful slurry-packing, it has been demonstrated that a minimum linear velocity of $1 \mathrm{~cm} / \mathrm{s}$ is required. Therefore, with increasing diameter of the column, it is more difficult and especially more expensive to find pumping systems capable of delivering large volumes of packing solvent at high linear flow velocity and pressure. The difficulties associated with slurry-packing preparative columns made it necessary to devise alter native approaches.

The technical solution of packing larger diameter preparative columns has to guarantee that the packing bed remains stable during the whole chromatography process. It is certainly a fact that conventional columns of larger diameter are less stable than analytical-size columns. Frictional heat, together with bridges and other instabilities formed during the packing process are the major reasons for this phenomenon.

\section{Frictional heat}

During transport of a mobile phase through a column, frictional heat is generated. The magnitude of this frictional heat does not only depend on the viscosity of the mobile phase, 


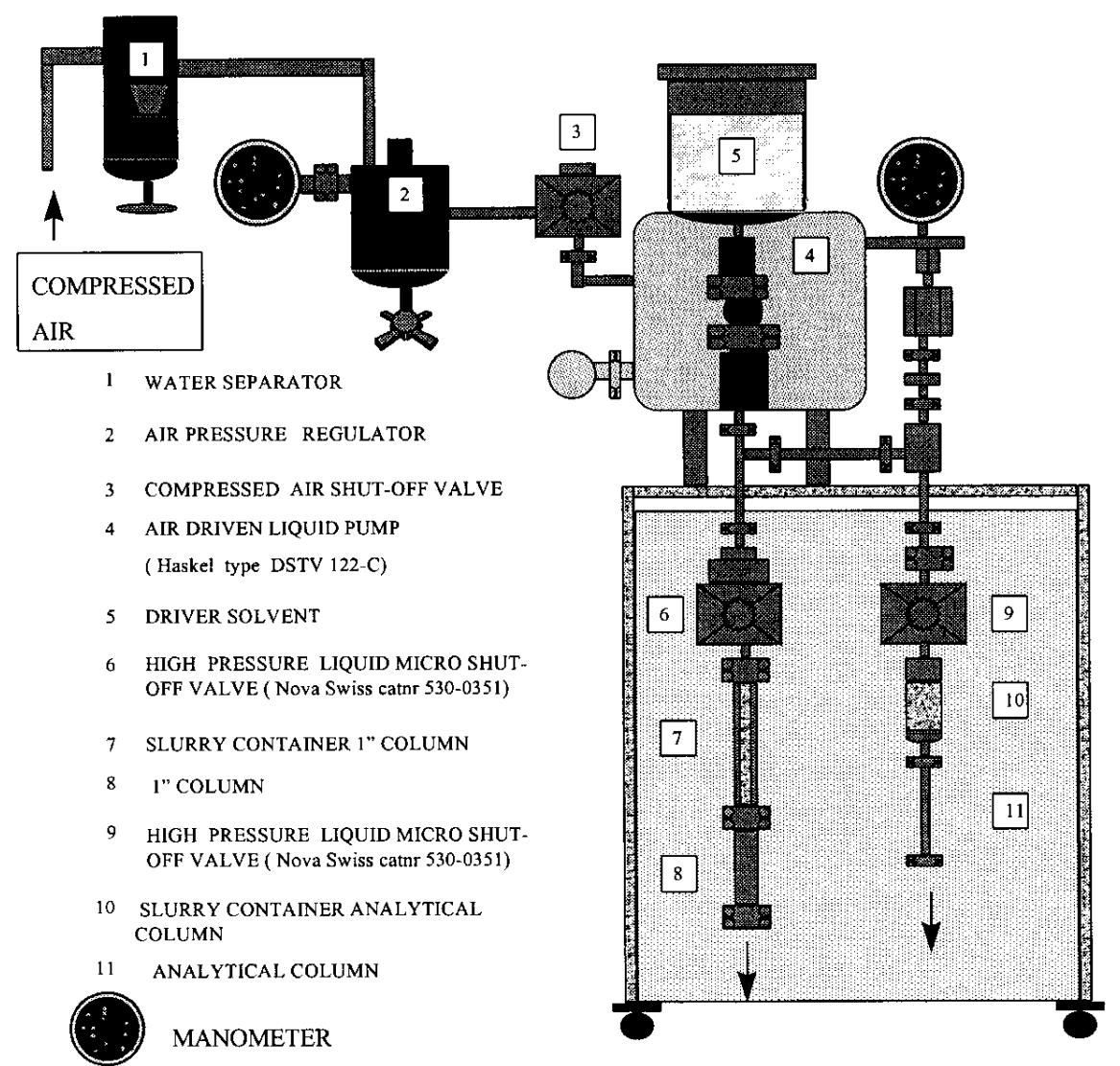

Figure 2. System for slurry packing of analytical and one-inch preparative columns.

Table I. Packing material - slurry solvent combinations.

\begin{tabular}{|c|c|c|}
\hline Packing material & Slurry solvent & Driver solvent \\
\hline $\begin{array}{l}\text { Si } 60(5-10 \mu \mathrm{m}) \\
\text { Kromasil (Akzo Nobel) }\end{array}$ & $\begin{array}{c}\text { Toluene - 2-propanol }(90-10 ; \mathrm{v} / \mathrm{v}) \text { or } \\
\text { Acetone - 2-propanol }(50-50 ; \mathrm{v} / \mathrm{v}) \text { or } \\
\text { CCl4 - methanol }(95-5 ; \mathrm{v} / \mathrm{v})\end{array}$ & n-Hexane \\
\hline $\begin{array}{l}\text { RP8 / RP18 }(5-10 \mu \mathrm{m}) \\
\text { Kromasil (Akzo Nobel) }\end{array}$ & $\begin{array}{c}\mathrm{CHCl}_{2}-2 \text {-propanol }(50-50 ; \mathrm{v} / \mathrm{v}) \text { or } \\
\mathrm{CHCl}_{3}-2 \text {-butanol }(50-50 ; \mathrm{v} / \mathrm{v})\end{array}$ & Methanol \\
\hline $\begin{array}{l}\text { Hypersil BDS }(8 \mu \mathrm{m}) \\
\text { (Shandon) }\end{array}$ & $\begin{array}{l}\text { Acetone }-\mathrm{CCl}_{4} \\
(50-50 ; \mathrm{v} / \mathrm{v})\end{array}$ & Methanol \\
\hline $\begin{array}{l}\text { Amino-propyl silica } \\
(5-10 \mu \mathrm{m}) \text { Kromasil } \\
\text { (Akzo Nobel) }\end{array}$ & $\begin{array}{l}\mathrm{CCl}_{4}-\text { methanol } \\
(95-5 ; \mathrm{v} / \mathrm{v})\end{array}$ & $n$-Hexane \\
\hline
\end{tabular}

but also on the mean particle size, the particle-size distribution and the pressure drop in the column.

- In normal-phase systems, the frictional heat is less important due to the use of low viscosity solvents, automatically resulting in low working pressures.

- When viscous mixtures of methanol-water or acetonitrilewater are used in reversed-phase systems, the frictional heat values are higher.
- Furthermore, the effect of frictional heat is more important in columns with larger diameters, because heat dissipation in such columns is more difficult.

Frictional heat effects act in two ways:

- The flow profile through the column is deformed, because the solvent viscosity is not the same throughout the whole cross-sectional area of the column. 
- The stainless-steel mantle of the column and the packing bed do not have the same thermal expansion coefficients. Through repeated thermal expansion and contraction, the packing bed changes and voids and gaps in the packing are produced, specifically at the top and along the walls of the column.

\section{Bridging}

During the slurry packing process, unstable particle bridges (as illustrated in Fig. 3) can be formed across the column diameter. These bridges remain stable during the packing procedure by the flow of slurry solvent.

As a result of friction forces or mechanical influences caused by the mobile phase flow or vibrations, these bridges can collapse, resulting in the formation of channels, voids and inhomogeneous dense packing. In analytical columns, the unstable regions are stabilised due to support from the column wall. The loss of wall support happens when the column diameter to column length ratio becomes larger than a certain limit value (not clearly known). Above this limit, the particles at the centre of the bed are not longer stabilised by the column wall. The way to solve this instability problem is to adapt the column volume continuously to the changing packed bed volume. This can be achieved by application of a continuous compression of the bed when the column is in use. Of course, the pumping of liquid through the column during chromato graphy also compresses the bed, but it does not change the column volume.

An experiment performed by researchers of Prochrom on a 50-mm ID column packed with $10 \mu \mathrm{m}$ ir regular silica has clearly demonstrated the usefulness of continuous compression of the packing bed. In the first experiment, the column was packed at 45 bar. After the packing process, $n$-heptane was pumped through the column at a flow rate of $150 \mathrm{~mL}$ pro minute and the bed quality was measured on a regular basis during a time period of 100 hours using toluene as the test substance. During the whole experiment a continuous compression of 45 bar was applied on the packed bed. The initially found value of 40000 theoretical plates per metre remained constant during the whole experiment. Thereafter the experiment was repeated using the same packing procedure, but after the packing process was completed, the bed was no longer compressed. The column performance was also measured for 100 hours using the same experimental conditions. Although initially the same column performance was measured as in the first experiment, after about 3 hours the efficiency was reduced to about half of the initial value. After 100 hours, it even dropped to about 20 per cent (Fig. 4).

To circumvent the technical problems accompanying the use of the classical slurry method for filling larger diameter preparative columns, new methods have been developed.

Godbille and Deveaux of the French Company Roussel Uclaf introduced the axial compression technology mid 1970's. Almost simultaneously Little and co-workers developed the radial compression technique.

Later on a few alternative techniques have been investigated and commercialised: (a) anaiytical column

(b) preparative column
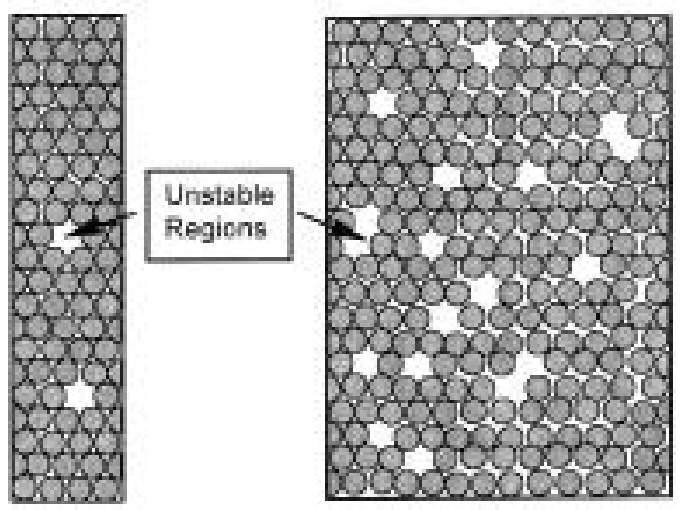

Figure 3. Packing structure (schematic drawing) a) analytical column b) preparative column.

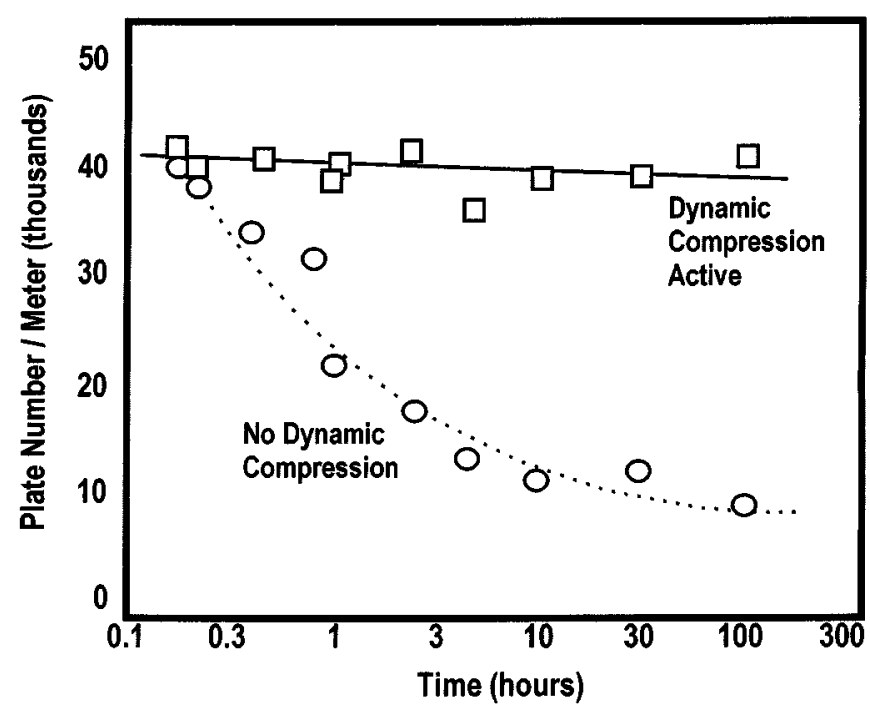

Figure 4. effect of constant pressurisation of a packed bed a) With dynamic compression b) without compression.

\section{Slurry-compression ram:}

The column is equipped with an additional reservoir of the same diameter (or a larger diameter) as the column and the compression of the packing is realised by means of a movable teflon piston.

\section{Annular expansion:}

A combination of radial and axial compression obtained by inserting a wedge shaped rod in the centre of the column that moves the piston upward.

\section{Vacuum filling combined with axial compression:}

The column is first filled with packing material using vacuum. The top flange is installed and the packed bed is axially compressed.

However, nowadays the whole large-scale column market is dominated by the standard axial compression technology. 


\section{Radial compression}

Flexible cartridges filled with packing material are placed in a container. The space between the column wall and the container can be pneumatically or hydraulically pressurised. During this compression process, the flexible wall is firmly squeezed around the packing (Fig. 5).

A disadvantage of this technology is the use of prepacked cartridges, which do not allow using different packing bed lengths. Furthermore, in this type of compression technique, particle size gradients always manifest themselves radially. Such a type of gradient has an influence on the radial velocity profile. Radial flow velocities are an impor- tant source of band broadening, because radial diffusion is too slow to compensate the concentration gradient generated by differences in flow velocity in the column cross sectional area.

\section{Axial compression}

From a conceptual point of view, it is the simplest of all compression techniques.

A system for axial compression (Fig. 6) consists of:

- a metal cylinder (about two times longer than the desired packing bed length) with a smooth internal surface, a)

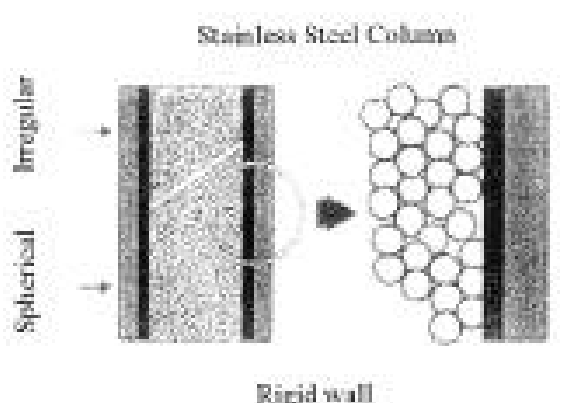

b)

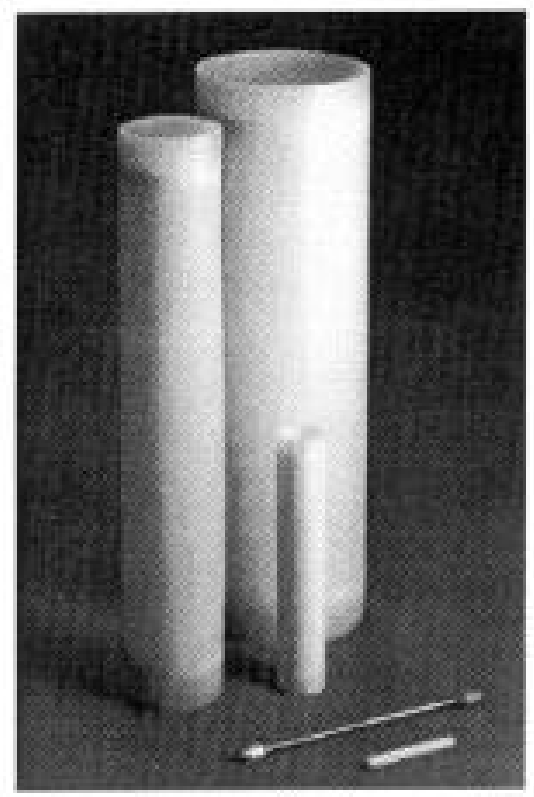

\section{Column with Ratis Cospression}



Flevible vall


Figure 5. Illustration of the radial compression principal a) schematic drawing b) cartridges and compression unit. 


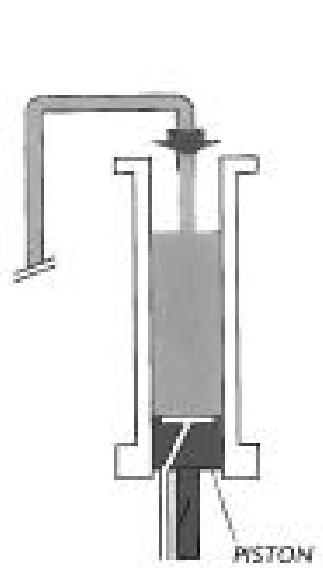
Slurry preparotion
and transfer

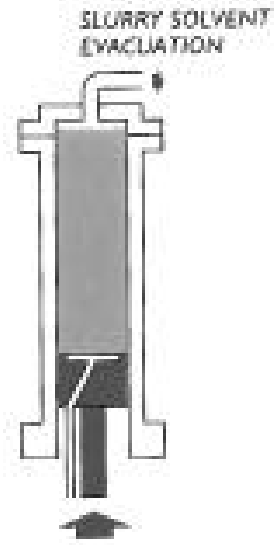

Column packing (2)
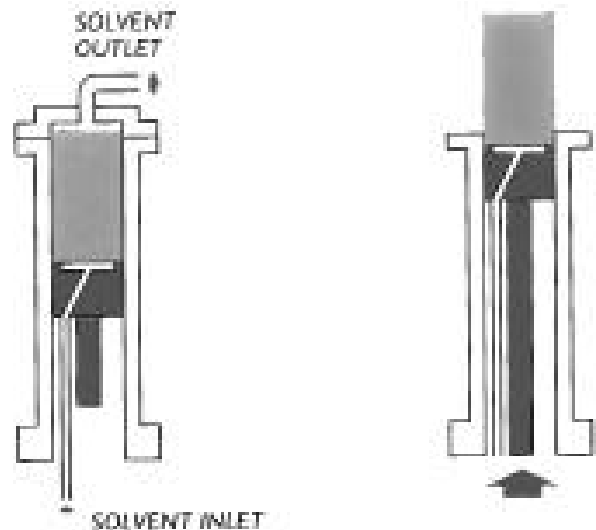

Sample purification

(3)
Column unpocking

1

Figure 6. Illustration of the axial compression technique.

- a piston equipped with a porous metal plate and seals that guarantee a leak free contact between the wall of the metal cylinder and the piston,

- a connection system between the piston and the hydraulic jack,

- a hydraulic jack with an air driven amplifier pump,

- a top flange with porous metal plate.

A homogeneous slurry of the desired amount of packing material in a suitable solvent is transferred into the cylinder. After completion of this operation, a top-flange is installed, and the piston is pneumatically or hydraulically moved upwards. The slurry solvent is removed through the porous metal plate in the top-flange. The pressure necessary to obtain a good quality column depends of the type of packing material that is used.

By means of the axial compression technique, it is possible to reproducibly fill columns. Furthermore, the packed bed is stable and the bed length can be easily adjusted over a broad range simply by choosing the amount of slurry. Interesting also is the possibility to remove the packing in a fast and clean way by means of the piston.

The axial compression technology allows without a lot of optimisation, to scale-up a chromatography process from a 50-mm internal diameter laboratory column to a large diameter column for Industrial applications.

\section{Prochrom system}

The dynamic axial compression columns of Prochrom (based on the patents of Roussel - Uclaf and Elf Aquitaine) are probably the best known and certainly for production purpose the most widespread of all types of axial compression preparative chromatography columns.

Figure 7 gives a schematic description of the dynamic axial compression column of Prochrom.

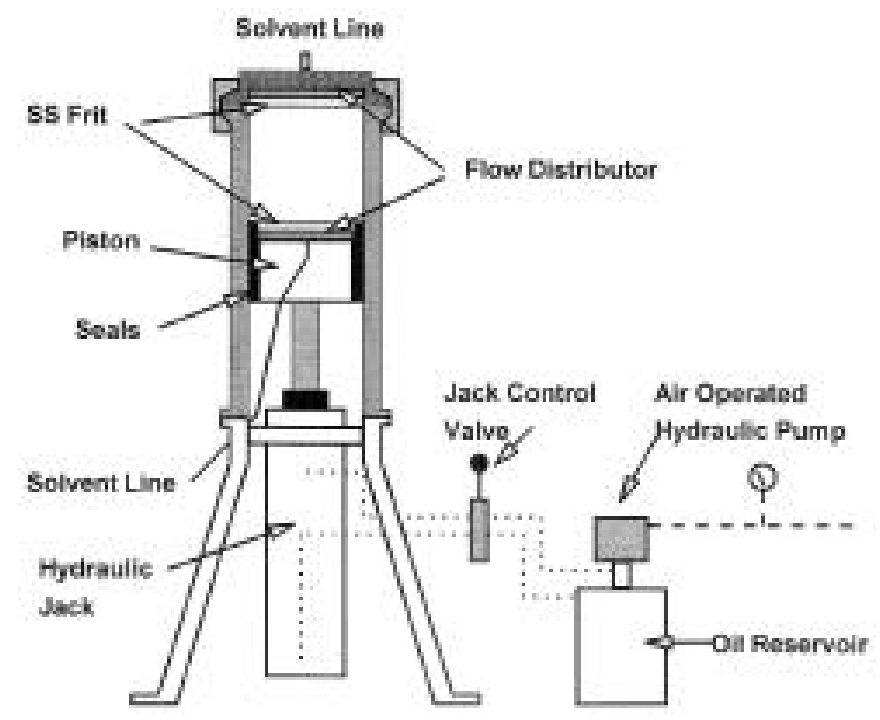

Figure 7. Schematic drawing of a Prochrom dynamic axial compression column.

The column contains a stainless steel piston, equipped with a set of specifically designed teflon seals (Fig. 8). These seals make a free movement of the piston possible and furthermore guarantee a leak free connection between the piston and the column wall.

The lower part of the piston is equipped with a pushing plate. This plate allows adjusting the pressure on the teflon seals, or in other words controls the sealing force between the piston and the column wall. The piston and the top flange are both equipped with a porous metal plate and a distribution system that takes care of a uniform distribution of the sample and the eluent across the sectional area of the column. The movement of the piston is realised by means of a hydraulic system, controlled by an air driven amplification pump (Haskel type) and a distribution system that 


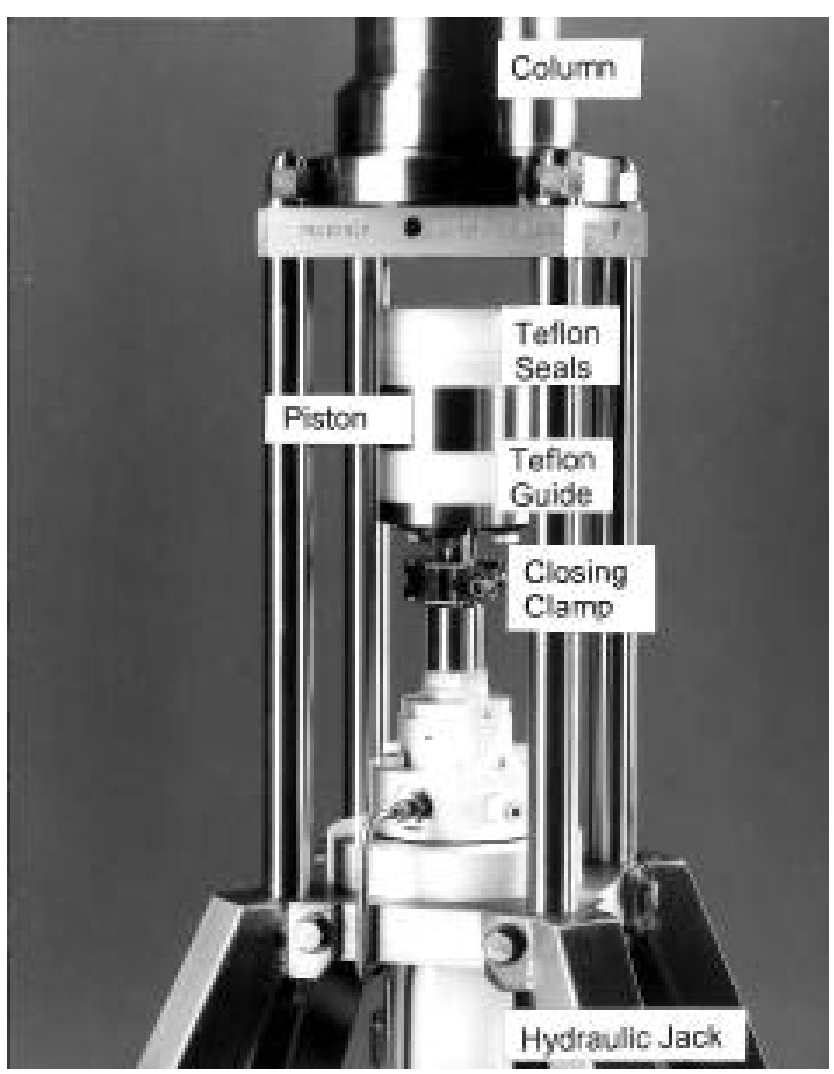

Figure 8. Detailed view of the piston and the teflon seals.

controls the direction of movement of the hydraulic cylinder. A compressed air supply between 0 and 6 bar allows a piston pressure between 0 and 70 bar, or 0 and 100 bar, depending on the column size.

This construction has the advantage, that there doesn't exist any danger for contamination of the eluent or packing material with hydraulic oil as a result of oil leakage from the cylinder. Furthermore, also interesting is that it is very easy to install the top flange by means of a quick sealing clamp.

The porous metal plates in the piston and the top flange are machined a little bit larger than their seats. By means of shrinking with dry ice or liquid nitrogen it is possible to install the porous metal plates leak tight. However, to guarantee a leak free installation, the way these metal plates are machined is very important. Only a small tolerance in diameter is allowed and furthermore the edges have to be very smooth and certainly without any holes or scratches.

Nowadays, two types of porous metal plates are available:

- The classical cintered plates of uniform porosity and

- The multi-layer plates.

The advantage of the classical plates is that they are easy to machine and relatively cheap.

The multi-layer plates assure a better distribution of the sample and eluent across the whole packed bed, but they definitely have some disadvantages:

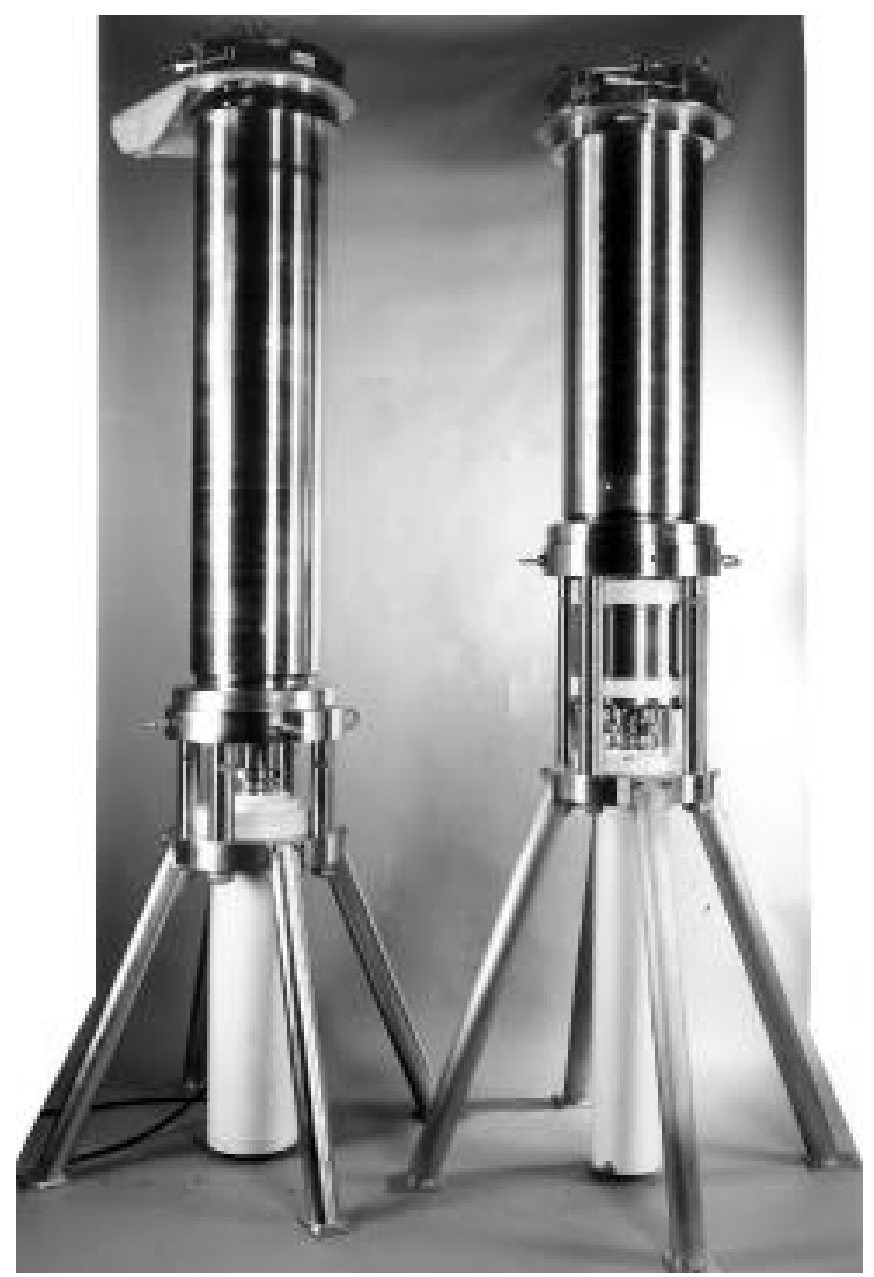

Figure 9. Typical Prochrom process type columns.

- It is very difficult to mechanically obtain the required uniform and smooth edges.

- They are a lot more expensive than the classical porous metal plates.

- Frequent removal of these plates with liquid nitrogen, often results in a separation of the layers due to their difference in thermal expansion coefficients or the presence of dirt in the pores, resulting in a worthless material.

Our strategy nowadays is to use the classical type of porous plates and to install new plates every time another production batch has to be performed, instead of using the better multi-layer plates and cleaning them between each chromatography batch.

Prochrom has a broad range of columns available. Starting from a test column of $50 \mathrm{~mm}$, over the classical 110 - 150 - $200-300$ and $450 \mathrm{~mm}$ internal diameter, it is possible to obtain columns of 600 and $800 \mathrm{~mm}$ ID. As well standard as custom designed column lengths can be ordered.

In the newest concept of Prochrom, the inverted configuration of column design is used (Fig. 10). The hydraulic cylinder is mounted above the column and the slurry is introduced via a specifically designed aperture in the wall of the column. The design of this aperture is of utmost importance, 
a)



II

4 b)

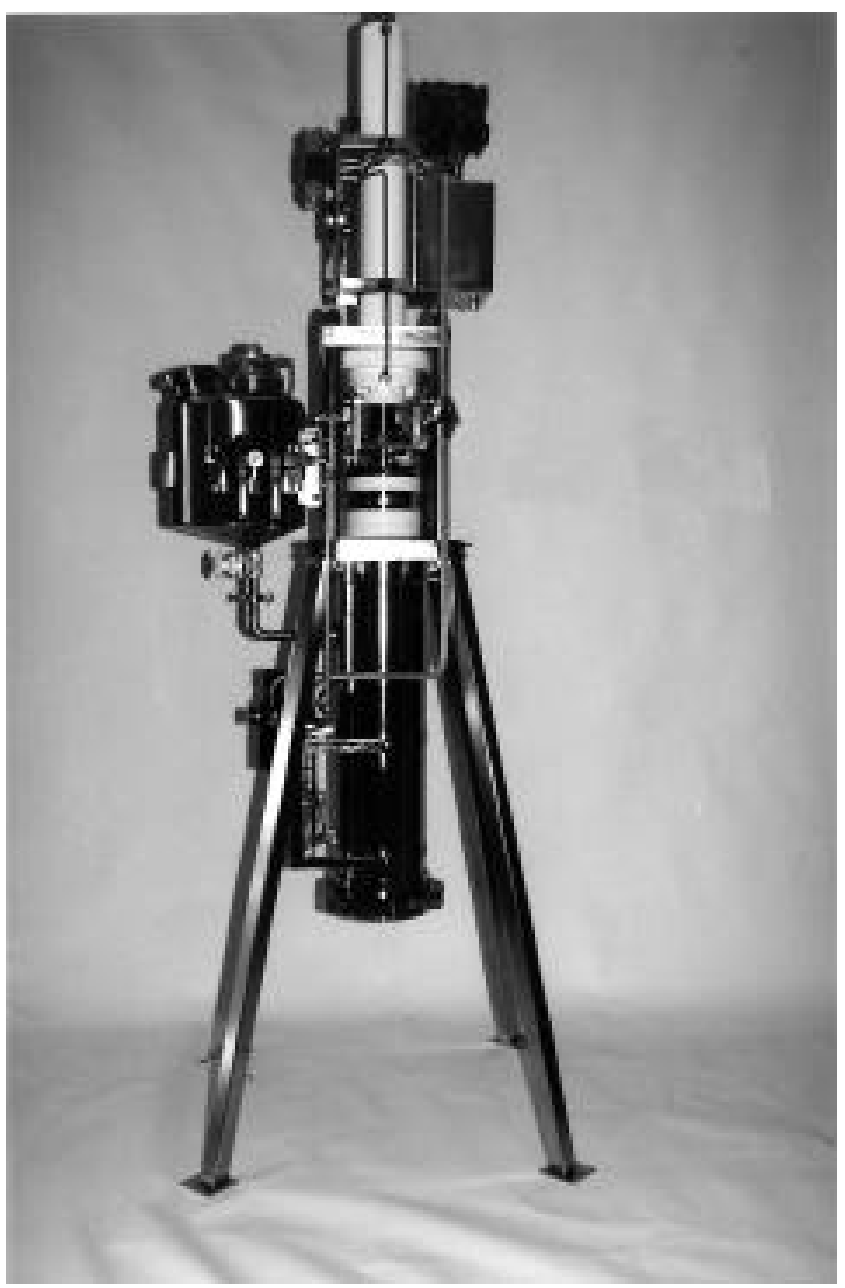

Figure 10. Prochrom inverted column design, a) Schematic drawing of the packing principle, b) $150 \mathrm{~mm}$ ID column.

if one considers that the seals of the piston having to be under sufficient tension (to assure a leak free contact with the column wall) should not wear off during the downward movement of the piston during compression of the packing. With the inverted configuration, it is also very important for GMP applications, to be able to prove that no contamination of the separated product can occur due to leakage of hydraulic oil.

The inverse concept is certainly very interesting when the user has to deal with the removal of packing materials that do not form the typical very rigid packing bed, normally obtained in dynamic axial compression. In the normal configuration with the hydraulic cylinder beneath the column, it is often difficult, without special measures, to remove some

specific stationary phases that do not form a solid cake, as for example some types of chiral stationary phases. In the case of the inverse concept, a clean removal of each type of packing bed is always guaranteed.

Furthermore interesting, especially for the pilot plant columns $(150-200 \mathrm{~mm}$ internal diameter) is the possibility to install adjacent to the column and above the aperture in the column wall, a small tank with a pneumatically operated stirrer to prepare a slurry of the stationary phase. Whether by means of gravity or with slight nitrogen overpressure, it is thereafter very easy to transfer the slurry into the column with practically no risk of contamination of the packing material by the surrounding atmosphere. 
Due to the fact that the patent on the dynamic axial compression technique is expired or will expire in most countries in the near future, it can be expected that more and more chromatography suppliers introduce their alternative of this technique on the market. However, for new comers, it will in our opinion be very difficult, to compete with both, the over the years developed high degree of confidence between the customers and Prochrom, and the enormous experience of this team in different fields of production scale preparative chromatography applications.

\section{Practical experience with the dynamic axial compression technique}

As well for medicinal chemistry as for development applications, we are standardised on slurry packed one-inch columns and dynamically compressed axial columns with an internal diameter ranging from $50 \mathrm{~mm}$ to $200 \mathrm{~mm}$.

For small scale applications (up to columns of $50 \mathrm{~mm}$ ID.) both $5 \mu \mathrm{m}$ Kromasil (Akzo-Nobel) and $8 \mu \mathrm{m}$ Hypersil BDS (Shandon) spherical packing materials are commonly used.

For pilot plant applications (up to $100-200 \mathrm{~kg}$ of product), we prefer to use spherical $10 \mu \mathrm{m}$ material (Kromasil). However, if we know for sure that we have to deal only once with a particular problem, we change more and more to the use of $20-40 \mu \mathrm{m}$ irregular silica, which offers relatively good performance at moderate price. After a chromatography batch has been completed, this material can be discarded without any heart feelings, which is not the case for the spherical materials.

For the packing of columns, different slurry solvent combinations have been investigated throughout the years. Nowadays, only a few combinations are left:

For Silica gel we normally use toluene in combination with 2-propanol in a volume ratio ranging from $90-10$ to $80-20$.

For reversed phase materials we prefer to use ethanol, acetone, or a mixture of methanol and 2-propanol in different ratios.

Normally the suspension contains one kilogram of packing material in three litres of slurry solvent. However, experiments have proven that within certain limits, the slurry concentration has practically no influence on the packing process of dynamically axial compressed columns.

Furthermore, experience with dynamic axial compression columns, has shown the limited mechanical stability of some types of packing materials. The application of a constant axial compression on a packed bed, often results in a tremendous decrease in permeability after a short period of time, although, analytical columns, slurry packed with the same material in the conventional way at pressures up to 500 bar and closed with the normal end fittings, remain stable. Therefore, the observed decrease in permeability for certain packing materials using the dynamic axial compression technology, certainly has something to do with the forces exerted by the movable piston. For an optimal use of the dynamic axial compression technique, the packing pressure certainly has to be considered as an important process parameter. Three criteria predominantly determine the packing pressure that has to be applied:
- As well the column efficiency as the peak shape can depend on the applied pressure.

- The packing pressure needs to be higher than the solvent pressure in the column to avoid a downward or upward (depending on the column configuration), movement of the piston.

- In order to avoid breakage of the particles, the packing pressure has to be kept below a certain critical value (typical of the packing material used).

The effect of the packing pressure on the column efficiency is illustrated in figure 11 .

The data in this experiment have been generated by researchers of Prochrom. The experiments were performed on a $80 \mathrm{~mm}$ ID dynamic axial compression column. A certain amount of material has been packed under exactly the same experimental conditions, but at different packing pressures. For every test fresh packing material from the same batch was used, except for the $\mathrm{C}_{8}$ material where the same packing has been re-used. After stabilisation of the column, the efficiency was measured at a certain flow-rate.

As clearly illustrated in figure 11 , for the spherical $\mathrm{C}_{8}$ material, above a certain minimum value, the packing pressure has no longer an influence on the column quality. A minimum packing pressure is probably required to circumvent the friction forces exerted by the piston seals on the column wall. The curves for the two other packing materials also confirm the necessity of a certain minimum pressure. However, for these materials it is clear that above a certain packing pressure value, the column efficiency decreases. In these experiments, simultaneously, an increase in elution pressure could be observed. These phenomena are likely to be the indication of the creation of fines due to breakage of particles. However, as long as the packing pressure is kept between the minimum and maximum value, the efficiency remains constant.

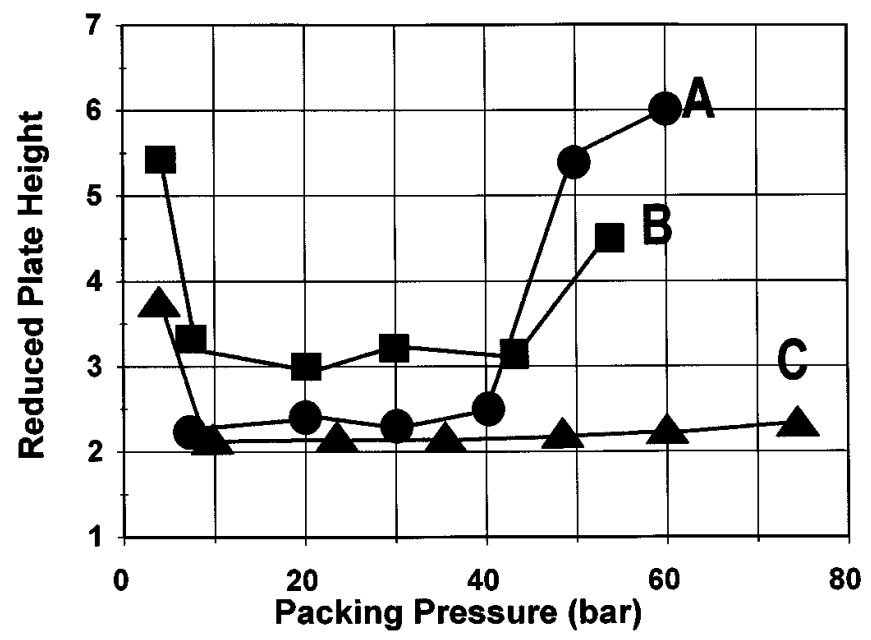

Figure 11. Effect of the packing pressure on the column efficiency, A) $12-45 \mu \mathrm{m} \mathrm{C}_{18}$ (irregular), B) Silica gel $5-45 \mu \mathrm{m}$ (irregular), C) $10 \mu \mathrm{m} \mathrm{C}_{8}$ (spherical). 


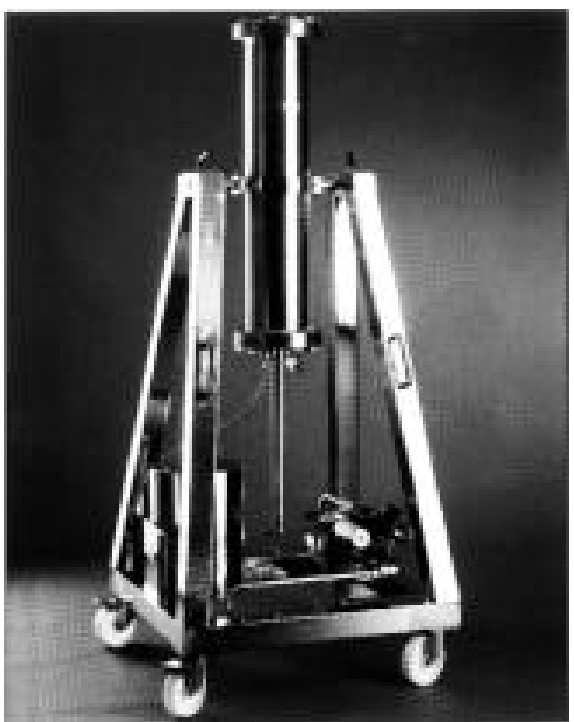

Figure 12. Dan process dynamic axial compression column.

\section{Dan process system}

Dan process offers a full line of dynamic axial compression columns ranging from $50 \mathrm{~mm}$ up to $600 \mathrm{~mm}$ internal diameter that can be used to a maximum pressure of 100 bars. The columns are installed in a frame by means of a hinge joint. This type of construction allows using the columns in the upright position during chromatography and turning the column upside down for easy emptying (see Fig. 12).

Instead of using a separate hydraulic cylinder, the axial movement of the piston is realised with solvent that is pumped into the column by means of a pressurised air driven amplification pump. The required amount of compression solvent (ethanol) is incorporated in the structure of the frame. In other words no additional reservoir has to be installed.

Both the top flange and the piston are equipped with a specially designed flow distribution system, which ensures a uniform distribution of the sample and the solvent across the whole packed bed.

Typical of the Dan process system is the use of relatively thin porous metal plates, which are welded in the piston and the top flange by means of a very specific welding technique to circumvent blockage of the pores in the vicinity of the welds. These thin porous plates are easier to clean than the thicker porous plates used in the Prochrom concept.

The piston in the column is designed in such a way that leakage of the compression liquid from one side of the piston to the other side is detected immediately.

Besides the high-pressure dynamic axial compression columns, Dan Process also offers stainless steel low-pressure columns of sanitary design in diameters ranging from 100 to $1200 \mathrm{~mm}$ ID with automatic bed height adjustment. These columns can be operated to a maximum pressure of 6 bar. Optional, it is also possible to obtain columns that can be used up to 10 bar.

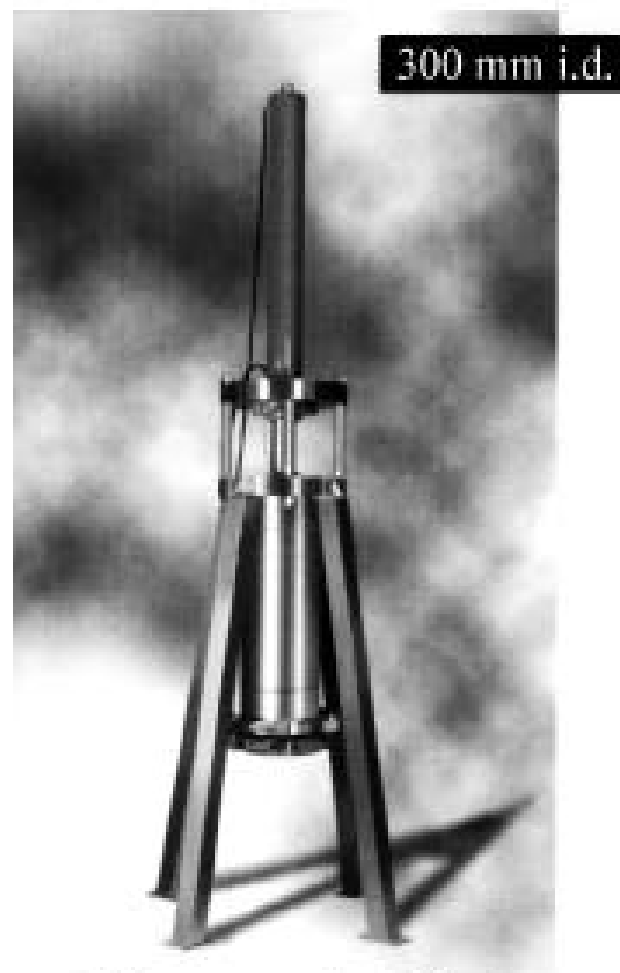

Axial compression ( 60 bar)

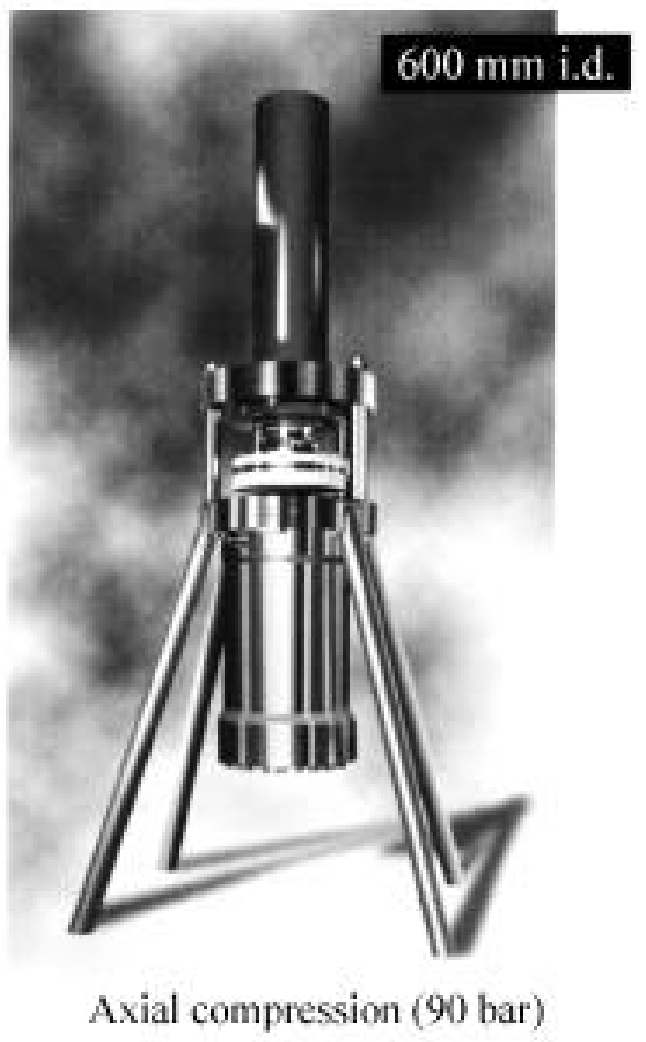

Figure 13. Novasep process type columm. 


\section{Novasep columns}

This company has a broad range of dynamic axial compression columns available. The columns can be offered in two standard versions, one type that can be used up to a maximum pressure of 60 bar the other type up to a maximum pressure of 90 bar.

Upon choice of the customer, the hydraulic jack can be installed above or beneath the column. Depending of the diameter of the columns and the desired maximum pressure rating, the top flange can be connected via fast sealing clamps or by means of bolts.

Both the piston and the top flange have a specifically designed flow distribution system. The porous metal plates in the piston and the top flange are welded to ensure a leak free installation. Standard column diameters are 100 - 150 $200-300-450$ and $600 \mathrm{~mm}$.

This company also offers stainless steel columns up to 1 metre in diameter for low pressure applications (10 bar). Furthermore, high pressure columns (up to 300 bar) for preparative supercritical fluid chromatography applications, as well as preparative gas chromatography columns and short columns for SMB applications are available.

\section{MODcol system}

In this method for slurry packing columns, a modular column design (Fig. 14a) is used. Two column bodies directly coupled via an adapter are employed in the packing instrument. One is being packed the other serves as a reservoir. The actual slurry packing is achieved through the use of a specially designed slurry-compression ram (SCRAM). This SCRAM is a cylinder-shaped, self-contained teflon piston (Fig. 14b) which fits inside the packing reservoir. For the forward displacement of the compression ram, a high-pressure, high capacity solvent delivery system is used.

This solvent delivery system is built up of two synchronised air amplification liquid pumps (Haskel: model DSTV 122) which create a safe and virtually pulsation-free solvent flow.

The packing process proceeds as follows (see Fig. 15):

An empty column is bolted to the reservoir column with the aid of a modular adapter. A self contained teflon packing piston is inserted in the bottom well of the reservoir column with the lip toward the pump for sealing. The packing end plate is bolted to the reservoir and connected to the solvent delivery system. Both the reservoir and the column are completely filled with a homogeneous slurry of the desired stationary phase in a suitable solvent and the end plate is bolted to the column. The transfer of pumping solvent into the bottom of the reservoir causes forward displacement of the movable packing piston. The piston continues to force the slurry into a compacted bed until the pre-selected packing pressure is reached.

This final packing pressure is determined by the packing pump pressure setting through the use of pressure relief or cut-off valves. Upon completion of the packing procedure, columns are remained at static pressure for some time to allow the packed bed to reach a stable equilibrium. After carefully unbolting the packed column from the reservoir and adapter, the packed bed is smoothed into a flat sheet fol- a)

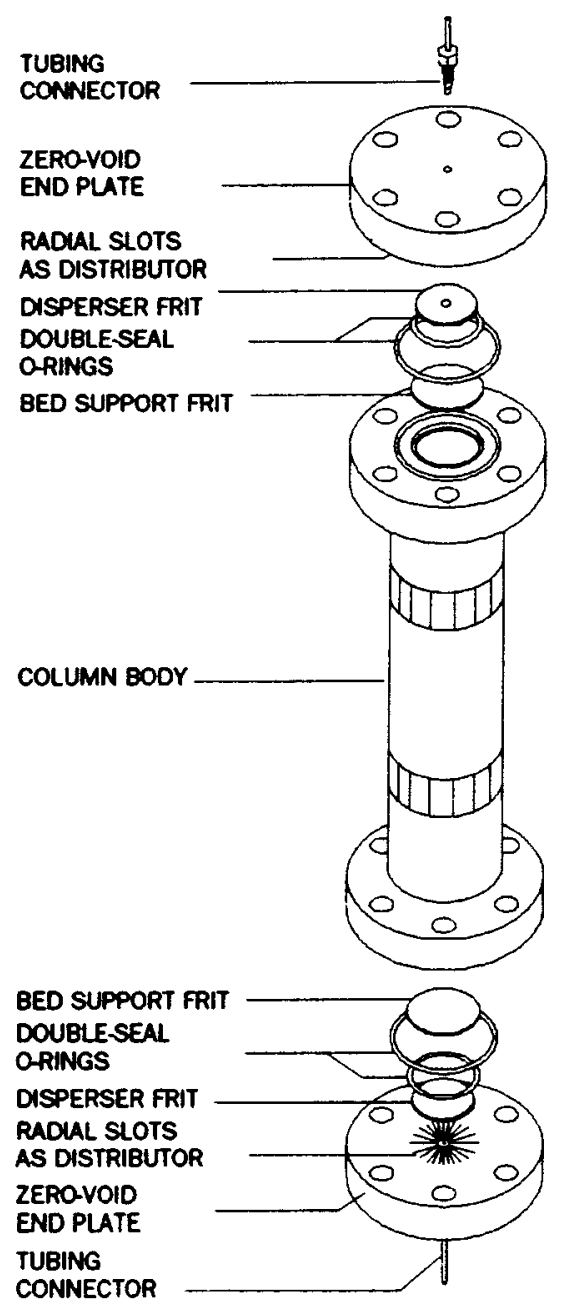

b)

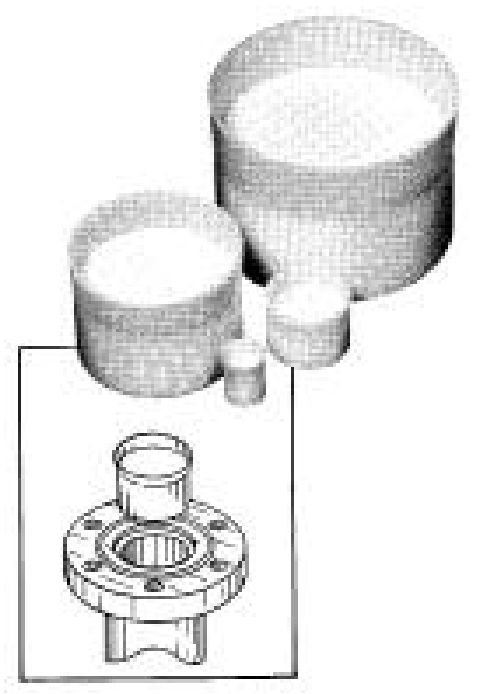

Figure 14. MODcol columns: a) column design, b) slurry compressor scram.

lowed by attachment of the porous metal plate, sealing Oring, and column end plate.

To improve the efficiency of packing and reduce the packing time, an air driven vibration device (unipacker) can be attached to the column during the packing process. 




Figure 15. MODcol Slurry packing assembly.

The MODcol parts and accessories offer al lot of flexibility:

- The straight adapter for example will securely connect two or more column bodies of the same internal diameter (Fig. 16a).

- The frit adapter is a modified straight adapter to allow insertion of a porous metal frit between column bodies. This type of adapter divides connected column bodies into two or more chambers for mixed-mode separations (Fig. 16b).

- The tapered adapter allows connecting one ID to the next larger column internal diameter (Fig. 16c).

- The MODcol Corporation offers an extensive line of standard flanged modular columns up to 4 inch in diameter and lengths between 30 and 100 centimetres. The maximum allowable pressure of these columns is 2000 psi (approximately 140 bar).

Also custom designed columns up to an internal diameter of $600 \mathrm{~mm}$ at various pressure ratings are available.

The company is furthermore well known for their slurry packing service of different packing materials.
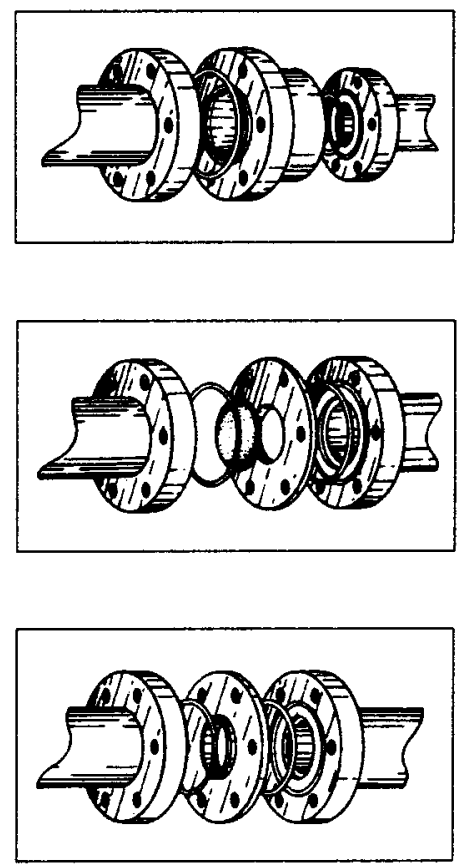

Figure 16. MODcol columns: Available adapters to connect columns: a) straight adapter, b) porous metal frit adapter, c) tapered adapter.

\section{The CEDI auto-axial compression cartridge system (Jones Chromatography)}

In this system, pre-packed plastic or stainless steel cartridges are used which are placed in a pressure resistant column holder (Fig. 17). At the head of this holder a piston is installed which acts as a hydraulic compression jack. A part of the eluent flow is used to supply the required axial compression force (Fig. 18). Therefore, the surface area of the piston in the column holder has been chosen in such a way that constantly a pressure be applied on the packing, which exceeds about $20 \%$ of the actual column pressure. Which in fact guarantees an optimal ratio between the eluent pressure and the axial compression of the packing bed.

Cartridges are available in diameter ranging from 25 to $150 \mathrm{~mm}$ with a length between 50 and $200-300 \mathrm{~mm}$. The standard holders for cartridges with an internal diameter of 25 and $50 \mathrm{~mm}$ allow the installation of 2 cartridges of $200 \mathrm{~mm}$ length. The holders for the $100 \mathrm{~mm}$ internal diameter cartridges are suited for the installation of 2 cartridges with a length of $300 \mathrm{~mm}$. The maximum working pressure rating is 100 bar (1500 psi). Furthermore a multi-holder (Fig. 19) is available which accommodates $50 \mathrm{~mm}, 100 \mathrm{~mm}$ and $150 \mathrm{~mm}$ cartridges.

The combination of two cartridges together with the possibility to use different flow circuits, allows the user to execute complex processes.

\section{Alternative packing techniques}

\section{Annular-expansion}

A technique developed by Separations Technology. This system uses a wedge shaped rod in the centre of the column 


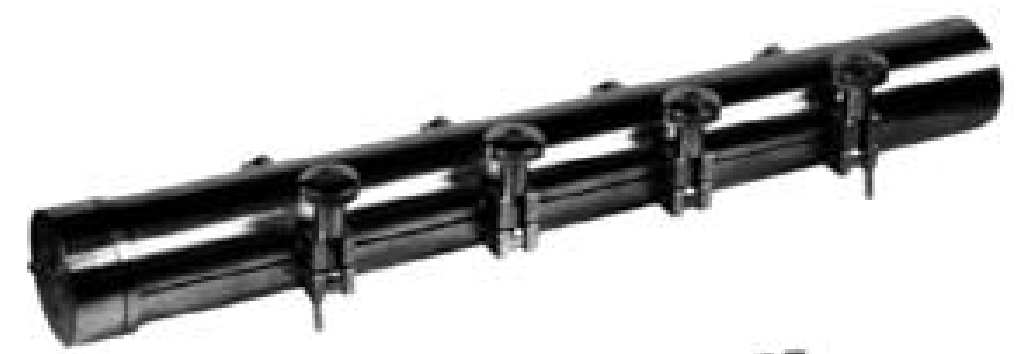



a.

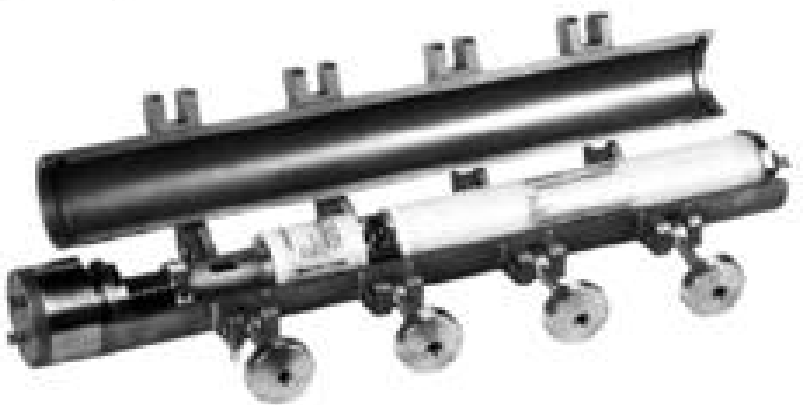

b.

Figure 17. Axial self-compression column, a) column holder, b) column holder with installed column and pre-column.



Figure 18. Schematic drawing of the axial self-compression.

that moves the piston upward. The upward movement of this rod is expected to combine both radial and axial compression of the packing bed. After installation of the piston, a

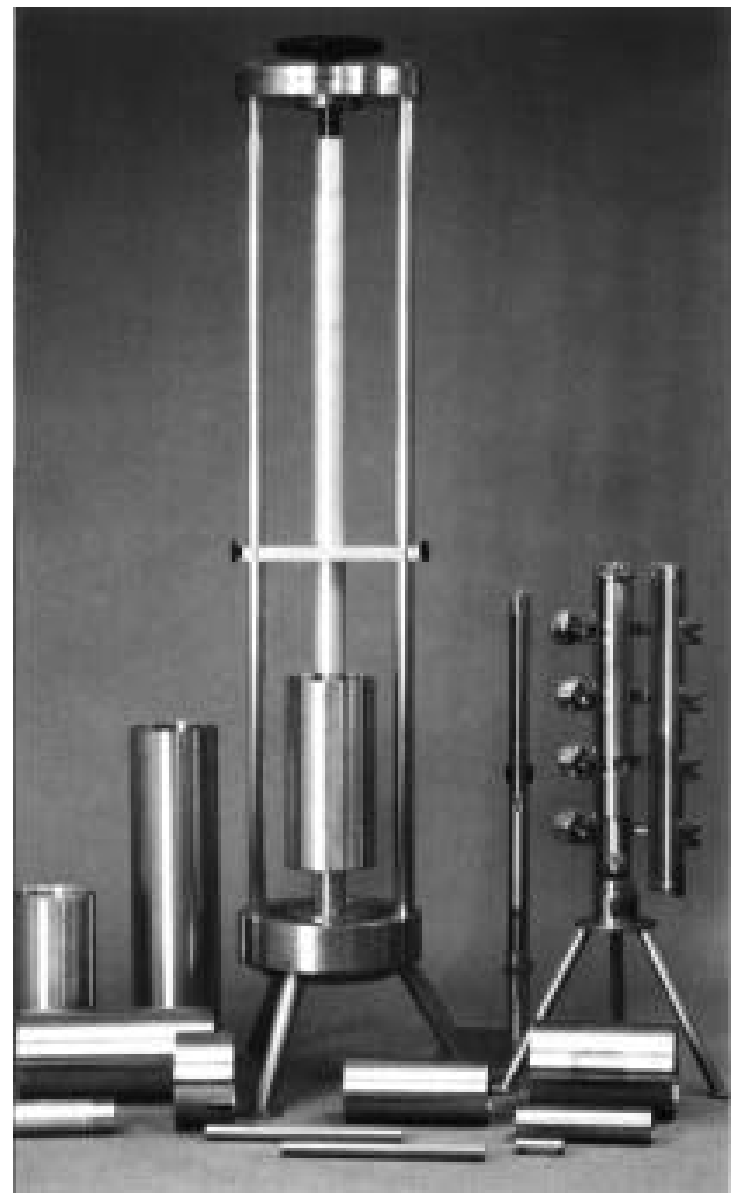

Figure 19. Multi-holder for axial self-compression columns.

column extension is installed on top of the column, then the slurry of stationary phase is introduced into the column, and the slurry solvent is removed by vacuum. When the column 
is fully packed, the column extension is removed, the outlet cap is attached and the packing bed is compressed by a hydraulic jack. The piston-tapered shaft assembly is forced through the packing bed exerting both radial and axial forces, and is locked into place when the bed has been compressed to the desired pressure (Fig. 20).

\section{The vacuum filling method}

Based on experience with the annular expansion columns, and observations on the behaviour of simple slurry packed glass columns after partial sedimentation of the particles, this technology was developed by the preparative chromatography group of Merck KGaA. The basic principle involved in this column packing method is the filtration of the particle suspension by means of a normal water jet vacuum followed by hydraulic packing bed compression.

\section{Packing procedure:}

Similar to the annular expansion technology, the piston is installed in the column and a packing reservoir is attached to the outlet flange of the column. The outlet tube of the piston is connected to a suitable trap to collect the slurry solvent. The outlet of this solvent trap is connected to a vacuum source. An ordinary water jet pump is sufficient to accomplish packing.

The desired amount of packing material is weighed in a suitable container and the required amount of slurry solvent is added. Acetone is used for reversed phase materials and methanol for bare silica. The suspension is stirred for about five minutes in an ultrasonic bath. The homogeneous suspension is poured into the column and the packing reservoir. Vacuum is applied and maintained until the top of the packing material seems to be free of solvent. After removal of the packing reservoir, the top flange is installed and the packing bed is compressed using the hydraulic jack.

Depending on the type of packing material, a different method has to be used to obtain good quality columns. For small particle diameters (between 5 and $15 \mu \mathrm{m}$ ), maximum vacuum has to be applied in the initial filtration process. Then the packing bed is stabilised by applying a moderate (40 bar) hydraulic pressure. To reach the optimum packing bed stability and peak symmetry, solvent has to be pumped through the column for about one hour using a high flow velocity. After this equilibration period the packing bed is hydraulically re-compressed and the piston is locked. For larger particles, the vacuum is regulated to achieve an even but not to fast sedimentation of the particles. Then the packing bed is stabilised by applying maximum hydraulic pressure and the piston is locked.

Packing stands (Fig. 21) are available to fill columns of 25, 50 and $100 \mathrm{~mm}$ ID. The maximum operating pressure is 100 bar (1500 psi). The columns can be used in the packing system or remote from the packing unit as a conventional column. If the column is used outside the packing unit, and the efficiency should decrease during operation, the column can be re-installed in the hydraulic packing unit, and re-stabilised. The hydraulic system itself can be used to pack additional columns. The vacuum packing technique can also be used to pack soft materials as, for example, polymer gels.

The same packing technology is used to fill cartridge type columns (PrepCart). Cartridges of 25 and $50 \mathrm{~mm}$ ID filled



Figure 20. Schematic diagram of the annular-expansion column illustrating the column packing process.

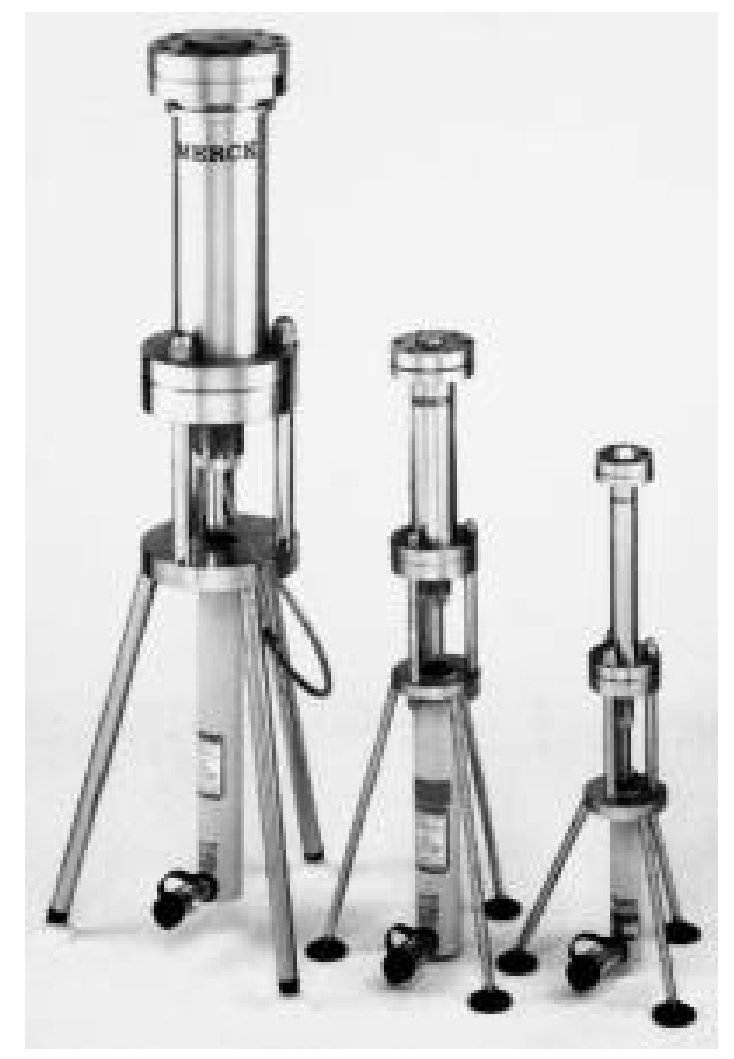

Figure 21. Packing-stand for vacuum filling.

with $12 \mu \mathrm{m}$ Lichrosper silica and reversed phase are available, but on demand it is also possible to obtain cartridges filled with other materials.

The standard length of the cartridges is $250 \mathrm{~mm}$. Precolumns with a length of $70 \mathrm{~mm}$ are also available. 
The cartridges are used in combination with the manuPrep hydraulic clamping unit, which allows to use the cartridges alone or in combination with a pre-column (Fig. 22).

The packing bed stability of these cartridges is very good as illustrated in figure 23 where the test results (peak symmetry, number of theoretical plates and reduced plate height) are depicted for a column treated under extreme conditions.



Figure 22. Prepcart cartridge with compression unit.

\section{Conclusions}

Due to the fact that only relative large particles can be dry packed, the practical usefulness of this packing technology is rather limited. However for particular applications in the medium pressure range, it can be a useful tool to perform preparative chromatographic separations without having to spend a lot of money in the investment of specific equipment.

As alternatives for the conventional slurry packing technique different techniques have been developed. The dynamic axial compression technology certainly has to be considered as the most flexible and reliable of all alternatives. This technique allows packing columns reproducibly with a very good efficiency and the obtained packed bed remains very stable due to the constant pressure applied on the bed. This technology is certainly the method of choice for production scale equipment.

As well the auto-axial compression system as the vacuum filled columns and cartridges are in our opinion useful tools for small-scale applications.

\section{Company addresses:}

\section{Prochrom}

5 rue Jacques Monod,

BP. 9,

Champigneulles F-54250,

France

\section{Dan Process A/S}

Gentoftegade 50-52,

DK-2820 Gentofte,

Danmark

\section{Novasep}

15 rue du Bois de la Champelle, BP. 50,

Parc Technologique de Brabois, Vandœuvre les Nancy F-54502,

France

\begin{tabular}{|c|c|}
\hline Date & Stress condition \\
\hline 15.01: & Test directly ofher colarme pocking \\
\hline 18.01 & Test oferer meekend operation \\
\hline 18.01. & Test afier 3 hours \\
\hline 19.01 & 2 hour shoke iest \\
\hline 2001 & 3hour shoke lest in forklat truck \\
\hline 27.01 & 40hour shake test in fork-liti mud \\
\hline 28.01 & Storage for 12 heus at $50^{\circ} \mathrm{C}$ \\
\hline $28.01:$ & 10 minutes ultrosonic bath of $20^{\circ} \mathrm{C}$ \\
\hline 28.01 & 30 minutes ulrosenic beth at 70 " $\mathrm{C}$ \\
\hline 03.02 & 20 heurs freezer of $-30^{\circ} \mathrm{C}$ \\
\hline 15.02 & 65 hours at high olvert How rote \\
\hline 1205 & Parmanemt cperction ofher 3 months \\
\hline
\end{tabular}

Siress test Prepcert*30

artrilges pected with UChrospher" RP-18 (12,um)

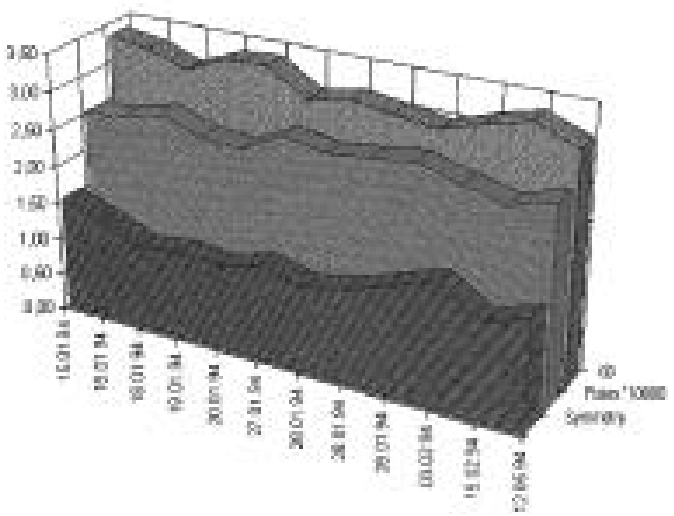

Figure 23. Stability of cartridges filled by the vacuum filling method. 
MODcol Corp

1266 Andes Blvd.,

St Louis, MO 63132,

USA

Jones Chromatography Ltd

Tir - y -Berth Industrial Estate,

New Road,
Hengoed Mid Glamorgan CF8 8AU,

UK

Merck KGaA

Frankfurterstrasse 250,

D-64271 Darmstadt 1,

Germany 